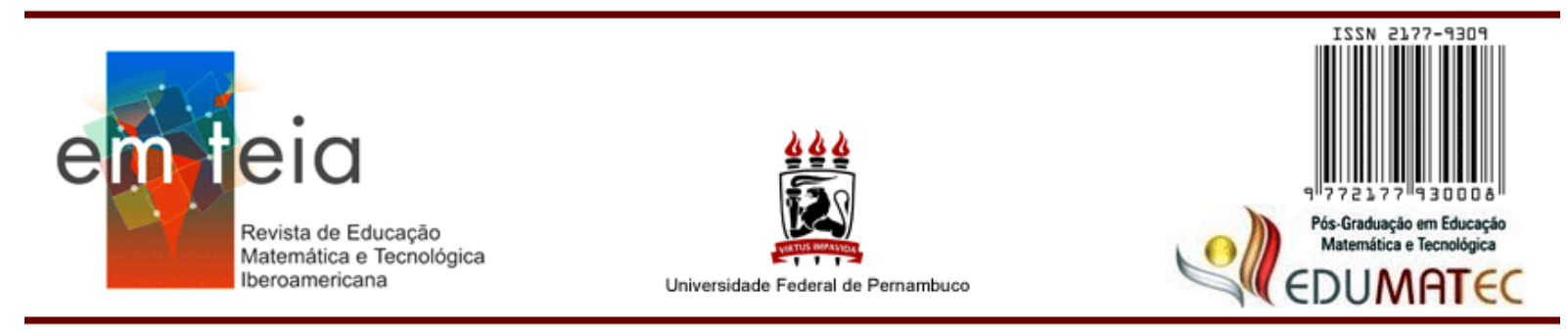

\title{
RESOLUÇÃO DE PROBLEMAS NO ENSINO DA MATEMÁTICA:
}

\author{
algumas considerações
}

\section{TROUBLESHOOTING IN MATH TEACHING:}

\section{Some considerations}

\author{
Eduardo dos Santos de Oliveira Braga
}

obeduardobraga@hotmail.com

\begin{abstract}
Resumo
O presente trabalho é um recorte da dissertação de mestrado do autor, intitulada por "Análise de pesquisas que tratam das Resoluções de Problemas amparadas pelas novas tecnologias no Ensino da Matemática", cujo objetivo foi realizar um levantamento de trabalhos acadêmicos que abordem a proposta de associação das Resoluções de Problemas e das Novas Tecnologias no Ensino da Matemática, de maneira vinculada. Porém, neste artigo, objetiva-se apresentar um quadro teórico a respeito da Resolução de Problemas no Ensino da Matemática. Para isso, primeiramente, investigamos o que vem a ser problema, apresentando algumas definições a respeito do assunto, atribuídas por diferentes autores. Com as conceituações postas, apresentamos o contexto histórico da Resolução de Problemas e sua ligação com o Ensino da Matemática. Intenciona-se, com isso, mostrar que a matemática e a Resolução de Problemas estão há tempos vinculadas, uma vez que o início de seu conhecimento parte da necessidade do homem em resolver problemas. Posteriormente, fazemos um levantamento bibliográfico sobre o assunto, apresentando seus objetivos, suas inferências - tanto na instituição escolar, quanto na vida do aluno e do professor - e trazemos algumas considerações a respeito de seu papel como metodologia de ensino. Por fim, de posse das leituras realizadas, identificamos alguns desafios e dificuldades que poderão ser encontrados na tentativa de implementar a Resolução de Problemas em sala de aula.
\end{abstract}

Palavras-Chave: Resolução de Problemas. Ensino da Matemática. Problema.

\begin{abstract}
The present work is an excerpt from the author's master's dissertation, entitled Analysis of research that deals with the Resolutions of Problems supported by new technologies in the Teaching of Mathematics, whose objective was to carry out a survey of academic works that address the proposed association of Resolutions Problems and New Technologies in the Teaching of Mathematics, in linked ways. However, in this article, the objective is to present a theoretical framework regarding the Resolution of Problems in the Teaching of Mathematics. For that, first, we investigate what is a problem, presenting some definitions on the subject, attributed by different authors. With the concepts put, we present the historical context of Problem Solving and its connection with the Teaching of Mathematics. It is intended, with this, to show that mathematics and Problem Solving have been
\end{abstract}


linked for a long time, since the beginning of its knowledge starts from the need of man in solving problems. Subsequently, we make a bibliographic survey on the subject, presenting its objectives, its inferences - both in the school institution, as well as in the life of the student and the teacher - and we bring some considerations regarding its role as a teaching methodology. Finally, with the readings taken, we identified some challenges and difficulties that may be encountered in the attempt to implement Problem Solving in the classroom.

Keywords: Problem Solving. Math Teaching. Problem.

\section{Para início de conversa...}

Este escrito é parte da dissertação de mestrado do autor, cujo objetivo foi realizar um levantamento de trabalhos acadêmicos que tratam da proposta de associação das Resoluções de Problemas e das Novas Tecnologias no Ensino da Matemática. Justifica-se a escolha da temática por questões tanto subjetivas, quanto pela própria pertinência e ascensão dos temas nos últimos anos quando o assunto é Ensino de Matemática. A subjetividade se encontra tanto nas formações acadêmicas anteriores do autor, quanto no estímulo e apreço pelas temáticas em sua prática profissional. Com relação ao tema tecnologias, a pertinência está na naturalidade que tem se dada à inserção das tecnologias na vida das pessoas que, por vezes, nem é perceptível o quanto estamos impregnados delas em nosso cotidiano (KENSKI, 2008). Com relação à Resolução de Problemas, a pertinência está na intrínseca relação que a metodologia Resolução de Problemas apresenta ao tornar mais acessível o aprender a aprender por parte dos alunos, característica esta que Demo (2015) considera como sendo o desafio do processo educativo, em termos propedêuticos e instrumentais, junto com o saber pensar.

Neste artigo, objetiva-se apresentar o seguinte recorte da dissertação: um quadro teórico a respeito da Resolução de Problemas no Ensino da Matemática. Assim sendo, não trataremos aqui das tecnologias no Ensino da Matemática, mas nos limitaremos a apresentar algumas considerações a respeito da Resolução de Problemas associada ao Ensino da Matemática. Pautamo-nos, com isso, numa pesquisa de cunho bibliográfico, numa perspectiva qualitativa, pois buscamos interpretar e compreender a realidade em que o objeto de pesquisa se enquadra, no caso, a Resolução de Problemas (MINAYO, 2009).

Inicialmente, investigamos o que vem a ser problema, apresentando algumas definições a respeito do assunto, atribuídas por diferentes autores. Com as conceituações postas, apresentamos um resumido contexto histórico da Resolução de Problemas e sua ligação com o Ensino da Matemática. Intenciona-se, com isso, mostrar que a matemática e a Resolução de Problemas estão há tempos vinculadas, uma vez que o início de seu 
conhecimento parte da necessidade do homem em resolver problemas. Posteriormente, fazemos um levantamento bibliográfico sobre o assunto, apresentando seus objetivos, suas inferências - tanto na instituição escolar, quanto na vida do aluno e do professor - e trazemos algumas considerações a respeito de seu papel como metodologia de ensino. Por fim, de posse das leituras realizadas, identificamos alguns desafios e dificuldades que poderão ser encontrados na tentativa de implementar a Resolução de Problemas em sala de aula.

\section{O que é problema?}

Inicialmente, é interessante destacarmos que consideraremos situação-problema e problema como sinônimos. Além disso, cabe enfatizar que, segundo Lorenzato e Vila (1993) e Verçosa, Rocha e Teles (2010), a noção do que é, de fato, um problema é difícil de se conceituar do ponto de vista da matemática. O termo problema está constantemente em utilização pelos professores de matemática, mas na maioria das vezes não vem acompanhado de uma reflexão a respeito de sua conceituação. Sua definição vai desde uma visão geral, do senso comum, como sinônimo de dificuldades e aperto, até as especificidades presentes no âmbito da matemática. Até mesmo as pessoas que não estão intimamente ligadas à matemática sugerem que problema seja uma palavra imprescindível do vocabulário, linguagem e vivência do professor de matemática. Muitos até veem a matemática como um dos seus sinônimos por considerá-la algo muito difícil e pouco prazeroso. Veremos aqui que há definições e ideias bastante sugestivas sobre o que é um problema.

Problema não se limita a exercícios que, por vezes, muitos livros didáticos apresentam de forma mecânica e repetitiva, como fixação de conteúdos, e dos quais alguns professores fazem uso como utensílio de adestramento na aplicação de determinada habilidade matemática. Aliás, cabe ressaltar que muitos materiais didáticos estão superando essa visão mais tradicional de ensino. Não estamos condenando o uso eventual dessa conduta, porém explicitando que Resolução de Problemas está distante disso. Dentre outros motivos, acreditamos que tal ação inviabiliza uma das importantes características proporcionadas ao se trabalhar sobre o pilar da Resolução de Problemas, que é a de fazer refletir e pensar criticamente por meio de uma situação-problema. O aluno deve ser capaz não só de realizar repetições, mas, principalmente, deve estar apto a "ressignificar em situações novas" e a "adaptar" e "transferir seu conhecimento para resolver novos problemas" (CHARNAY, 1996, p. 38). 
A Matemática não é um esporte para espectadores; não se pode desfrutar dela nem aprendê-la sem a participação ativa; por isso o princípio da aprendizagem ativa é particularmente importante para nós, professores de matemática, especialmente se considerarmos como nosso principal objetivo, o primeiro de nossos objetivos, o de ensinar o estudante a pensar (PÓLYA, 1995, p. 10.)

Uma das definições para Problema pode ser encontrada nos escritos de Thompson (1989), conforme citado por Allevato (2005). Lá temos implicitamente uma descrição que diz que a importância do problema se dá na obtenção de uma resposta. O problema estará resolvido a partir do momento em que temos um resultado final. A ênfase está no fim, o que sugere uma desconsideração na relevância do processo e dos caminhos para se obter o resultado em questão. Para o autor, o problema é a descrição de uma situação envolvendo quantidades pré-determinadas com um questionamento cuja resposta exige a aplicação de uma ou mais operações aritméticas.

Para Charnay (1996), o conceito de problema se aproxima mais de uma possível definição mais generalizada, pois o autor o associa à dificuldade e a um obstáculo a ser superado.

Só há problema se o aluno percebe uma dificuldade; uma determinada situação que 'provoca problema' para um determinado aluno pode ser resolvida imediatamente por outro (e então não será percebida por este último como sendo um problema). Há então, uma idéia de obstáculo a ser superado (CHARNAY, 1996, p. 46).

O Parâmetro Curricular Nacional - PCN (BRASIL, 1997) preconiza a Resolução de Problemas como um dos caminhos para se fazer matemática em sala de aula e define problema matemático como sendo "uma situação que demanda a realização de uma sequência de ações ou operações para obter um resultado. Ou seja, a solução não está disponível de início, no entanto é possível construí-la” (p. 32-33). Segundo Pozo e Echeverría (1998), problema está relacionado a questões abertas que exigem um posicionamento dinâmico do aluno.

\footnotetext{
A solução de problemas baseia-se na apresentação de situações abertas e sugestivas que exijam dos alunos uma atitude ativa ou um esforço para buscar suas próprias respostas, seu próprio conhecimento. $\mathrm{O}$ ensino baseado na solução de problemas pressupõe promover nos alunos o domínio de procedimentos, assim como a utilização dos conhecimentos disponíveis, para dar resposta a situações variáveis e diferentes. (POZO; ECHEVERRÍA, 1998, p. 09).
}

Dante (1988), segundo Cavalcanti, Branco e Santos (2011, p. 5), diz que Problema “é a descrição de uma situação onde se procura algo desconhecido e não temos previamente 
nenhum algoritmo que garanta a sua solução". Para ele, problemas não são como exercícios. Estes seriam ferramentas para praticar determinado processo ou algoritmo matemático. Já aquele exige processos mentais mais complexos e desafiadores. Já no ano 2000, Dante (2000) define um problema como sendo "qualquer situação que exija o pensar do indivíduo para solucioná-lo" (p. 9) e problema matemático como sendo "qualquer situação que exija a maneira matemática de pensar e conhecimentos matemáticos para solucioná-lo" (p. 10).

Segundo Costa e Allevato (2010), um problema está relacionado a certo distanciamento de memorizações, regras e fórmulas. $\mathrm{O}$ aluno, com isso, não está preso a um método de solução que o limita a desbravar novos conhecimentos. Além de fazer com que os estudantes compreendam que não há um método correto específico de solução para determinado problema. Já segundo Lupinacci e Botin (2004), a Resolução de Problemas é um método a ser utilizado pelo professor, ao ensinar determinado conteúdo de matemática, que distancia a falta de interesse por parte dos alunos, uma vez que os desafia através da exploração do problema.

A resolução de problemas é um método eficaz para desenvolver o raciocínio e para motivar os alunos para o estudo da Matemática. O processo ensino e aprendizagem pode ser desenvolvido através de desafios, problemas interessantes que possam ser explorados e não apenas resolvidos. (LUPINACCI; BOTIN, 2004, p. 1).

Segundo Alvarenga e Vale (2007), problema é aquilo com o que nos deparamos e não sabemos, em primeira mão, como enfrentá-lo. É necessário, para isso, processos mentais e estratégias que deverão estar relacionadas à criatividade e à curiosidade.

É consensual que se está perante um problema quando a situação não pode ser resolvida pelo recurso imediato a processos conhecidos e estandardizados. A procura da solução envolve o recurso adicional de processos mentais que podem ajudar a chegar à solução e que constituem um apoio para que os alunos consigam, com entusiasmo e sucesso, resolver problemas. Estes processos são vulgarmente designados por estratégias de resolução de problemas e estão mais associados à criatividade e à curiosidade, que à aplicação rotineira de um conjunto de técnicas sem significado. (ALVARENGA; VALE, 2007, p. 29).

Van de Walle (2001) vê a definição para problema como qualquer atividade ou tarefa em que não conhecemos um método já estabelecido ou regras prescritas e memorizadas para sua correta solução. Ressalta ainda que não há um método específico para chegar à solução correta do problema. Para Lester (2012), problema é sinônimo de tarefas matemáticas que possibilitam, por meio de desafios, a progressão matemática no aluno. Ainda segundo o autor, 
o termo Resolução de Problemas se refere a "tarefas matemáticas que têm o potencial de proporcionar desafios intelectuais para melhorar o entendimento e desenvolvimento matemático dos estudantes" (p. 148).

Posto algumas dessas definições e ideias a respeito do que é um problema, cabe a nós nos posicionarmos no sentido de apresentar a visão que queremos atribuir para definir um problema. Sendo assim, em consonância com alguns autores, ao tratarmos sobre situaçãoproblema, estaremos considerando muito mais o processo que o aluno estará utilizando, bem como sua execução, do que a resposta final. Nesse sentido, é evidente que, se a maneira de se trabalhar com determinado problema estiver bem encaminhada, atentando-se para sua execução, a resposta final será meramente uma consequência. Assim, assumiremos nesta pesquisa como concepção para problema questionamentos para os quais o aluno não possua ferramentas prontas e, de imediato, conhecidas para resolvê-lo; ainda assim, mostram-se interessados em buscar e investigar caminhos para solucioná-los. Isso vai além de desafios; são inquietudes que determinadas questões podem trazer para o aluno e que o levem, de forma ativa e crítica, a avançar na matemática e a desbravar novos conceitos e propriedades por meio de sua própria investigação e pesquisa.

\section{Breve histórico da resolução de problemas}

A Matemática e a Resolução de Problemas estão há tempos vinculadas, não com o olhar que atribuímos hoje a essa relação, mas com o viés de solucionar questões ligadas às dificuldades vivenciadas cotidianamente pelos povos. Segundo Onuchic (1999), há registros de problemas encontrados desde a história antiga egípcia, chinesa e grega. O Papiro de Moscou, por exemplo, foi escrito aproximadamente em 1890 a.C., e são problemas que o compõem. Remonta, com isso, a quão longínqua pode ser a concepção de problema e suas mais variadas maneiras de serem observadas. Sobrevivência, dificuldades do dia a dia dos povos, diversão/passatempo são algumas das relações que podem ser encontradas para problema. Posteriormente, é com o avançar das ciências que o olhar para problema se volta ao ensino e toma outras proporções como as de fixação de conteúdo. Mesmo com o avanço das concepções acerca do sentido de problema e sua utilização, ainda guardamos ideias presentes no tempo antigo para a sua conceituação. Prova disso são algumas das definições apresentadas na seção anterior.

A história da matemática nos mostra a importância dos problemas. Por trás de muitas das descobertas matemáticas, havia sempre problemas que motivaram o nascimento de 
conceitos e teorias. É indubitável que, na História da Matemática, muitos problemas tenham significações especiais, que agem como catalisadores influenciando significativamente o desenvolvimento da Ciência. Esses problemas atraem e fascinam pesquisadores muito por conta da simplicidade e lucidez de seus enunciados. Como resultado, há o desenvolvimento de diversos métodos, e novas teorias e perguntas, profundas e abrangentes, são formuladas (RAIGORODSKI, 2004).

A Duplicação do Cubo, a Quadratura do Círculo e a Trissecção do Ângulo são exemplos de clássicos problemas da Matemática Grega que desempenharam importante papel no desenvolvimento da matemática (CARVALHO, 2010). Ainda hoje há alguns problemas em aberto que levam diversos matemáticos a dedicarem suas vidas em busca de possíveis soluções. Sem contar que quem conseguir solucioná-los poderá ser financeiramente bem recompensado. Artur Avila - ganhador da medalha Fields por suas profundas contribuições na área da matemática, com ênfase em Sistemas Dinâmicos - é um exemplo atual de matemático que se dedicou à Resolução de um Problema durante anos. Avila, junto com a matemática Svetlana Jitomirskaya, em 2005, provou a "Conjectura dos dez Martínis ${ }^{1 "}$ que é um problema proposto em 1980 pelo norte-americano Barry Simon e para o qual, até então, não havia solução. Percebe-se que problema e matemática, há tempos, de forma colaborativa, caminham juntos, e que existem diferentes formas de concepção ao decorrer dos anos.

George Pólya, em 1945, foi um dos primeiros a tratar de maneira mais consistente a Resolução de Problemas no Ensino da Matemática. Todavia, foi no final dos anos 1970 que a Resolução de Problemas ganhou maior destaque em todo o mundo. As discussões voltadas para a Educação Matemática, no Brasil e fora dele, começaram a revelar as novas tendências no campo da matemática e a necessidade de adaptá-las ao contexto escolar em busca de melhorias na relação de ensino e aprendizagem.

Foi na década de 1980 que o assunto se tornou ainda mais forte, com a publicação nos Estados Unidos da An Agenda for a Action, traduzida como Agenda para Ação do NCTM (National Council of Teachers of Mathematics). Nela, o Conselho Nacional de Professores de Matemática, que é a principal organização profissional para professores de matemática - sem fins lucrativos - teve a intenção de apresentar seus olhares para as questões educacionais que, antes, eram mais fomentadas pela opinião pública. Segundo Onuchic (1999), esse conselho foi quem sugeriu, na perspectiva de promover uma educação voltada para todos, a Resolução de

1 AVIla, A.; JitOMIRSKAYA, J. The Ten Martini Problem. Annals of Mathematics, v. 170, p. 303-342, 2009. 
Problemas como foco da matemática para os anos 1980, pois foi a partir desta década que os educadores matemáticos passaram a aceitar a ideia de que resolver problemas necessitava de atenção. Porém, por ser uma proposta inovadora, existiam diversificadas concepções para a questão de a Resolução de Problemas ser o foco da matemática escolar nos anos 1980. Prova disso foram os muitos recursos desenvolvidos em Resolução de Problemas que não culminaram em bons resultados por conta dessas divergências.

A partir das diferentes concepções existentes para o assunto na época, Schroeder e Lester (1989) propuseram três diferentes olhares para a Resolução de Problemas: ensinar sobre Resolução de Problemas; ensinar para resolver problemas; e ensinar através da Resolução de Problemas. Ensinar sobre Resolução de Problemas seria ensinar o assunto Resolução de Problemas como uma nova teoria. Seu surgimento se dá, principalmente, como uma opção para tentar superar o fracasso da aprendizagem matemática e estimular os educadores da área com a implementação de uma nova teoria. Ensinar para resolver problemas de matemática vem como uma tentativa de resolver os problemas que o Ensino da Matemática moderna vinha apresentando. O professor, segundo Schroeder e Lester (1989), utiliza o que se ensina na matemática para transformar isso em problemas simples ou não tão simples assim. Seu olhar está na capacidade do aluno em transferir o que lhe foi ensinado para resolver problemas. É visto, com isso, como um instrumento a ser utilizado após a posse de novos conceitos ou após a prática de certos algoritmos. O problema aqui não antecede as novas descobertas, mas faz uso delas para atacá-lo.

Já ensinar matemática através da Resolução de Problemas consiste numa metodologia de ensino. Não é um novo conceito a ensinar, nem mesmo é parte de um conteúdo, mas é um essencial meio de se fazer matemática. O professor, por sua vez, faz uso da Resolução de Problemas como uma metodologia de ensino, aprendizagem e avaliação ao propor situaçõesproblema que levem o aluno a se tornar ativo na construção de sua própria aprendizagem e ao proporcionar que o discente assuma um papel de pesquisador nas investigações propostas pelo problema. Na prática, Schroeder e Lester (1989) ressaltam ainda que os três olhares expressos acima para a abordagem da Resolução de Problemas podem se estabelecer em diferentes momentos do ensino e, inclusive, de forma sobreposta.

Dificilmente o aluno de Matemática testemunha a ação do verdadeiro matemático no processo de identificação e solução de problemas. O professor faz questão de preparar todos os problemas a serem apresentados com antecedência; consequentemente, o legítimo ato de pensar matematicamente é escondido do aluno, e o único a conhecer a dinâmica desse processo continua sendo o professor. O professor, com isso, guarda 
para si a emoção da descoberta de uma solução fascinante, da descoberta de um caminho produtivo, das frustrações inerentes ao problema considerado e de como um matemático toma decisões que facilitam a solução do problema proposto. O que o aluno testemunha é uma solução bonita, eficiente, sem obstáculos e sem dúvidas, dando-lhe a impressão de que ele também conseguirá resolver problemas matemáticos com tal elegância (D`AMBRÓSIO, 1993, p. 36).

O húngaro e professor de Matemática Pólya (1887 - 1985) foi um dos primeiros a publicar uma obra sobre Resolução de Problemas. De acordo com Andrade (1998, p. 7),

A primeira vez em que a resolução de problema é tratada como um tema de interesse para professores e alunos, nos níveis superiores, foi a partir do livro How to solve it, de Pólya, cuja primeira edição data de 1945. Antes desse período, entretanto, houve algumas experiências e alguns estudos enfatizando os produtos da resolução de problemas. As experiências mais remotas e significativas podem ser creditadas a Dewey, entre 1896 e 1904. Nessas experiências, as crianças estudavam através de projetos que reproduziam as situações socioeconômicas (estudo/resolução de problemas de interesse da comunidade).

A proposta de Pólya se baseava em tornar os alunos ótimos resolvedores de problemas. Os escritos de Pólya se tornaram referência para os educadores dedicados à matemática. Para ele, resolver problema é uma arte; ainda define quatro fases para a Resolução de qualquer Problema Matemático, são elas: compreensão do problema, construção de um plano de resolução, execução deste plano e retomada para conferência e verificação da solução do problema. Para Pólya (1995, p. 18-19), "uma grande descoberta resolve um grande problema, mas há sempre uma pitada de descoberta na resolução de qualquer problema". E é essa descoberta que poderá desencadear no aluno o interesse pelo exercício da mente. Até porque, segundo ele, são os problemas que tomam boa parte do nosso pensamento consciente, e a resolução dos mesmos exerce papel fundamental na atividade humana.

Quadro 1 - Fases da Resolução de Problemas segundo Pólya

\section{FASES}

Compreensão do Problema

Construção de um Plano de Resolução

\section{BREVE DESCRIÇÃO}

Busca compreender o problema a fim de encontrar sua incógnita. É nesta fase que há o reconhecimento dos dados conhecidos, bem como a determinação do objetivo a ser alcançado.

Elabora-se, de posse da compreensão dos problemas, os cálculos e caminhos a percorrer no intuito de obter a incógnita. Importante a concepção deste plano para 


\begin{tabular}{|c|c|}
\hline $\begin{array}{c}\text { Execução do Plano de } \\
\text { Resolução }\end{array}$ & $\begin{array}{c}\text { Sua futura execução. } \\
\text { Coloca-se em prática o plano elaborado, } \\
\text { examinando todos os detalhes decorrentes de sua execução. } \\
\text { Caso haja contratempos, volta-se à fase anterior para } \\
\text { elaboração de um novo plano. }\end{array}$ \\
\hline $\begin{array}{c}\text { Conferência e Verificação } \\
\text { dos Resultados }\end{array}$ & $\begin{array}{c}\text { Em consonância com o raciocínio inicial, verifica-se } \\
\text { o resultado fazendo uma revisão crítica da execução de } \\
\text { todo o plano traçado. }\end{array}$ \\
\hline
\end{tabular}

Fonte: o Autor.

Em 1997, os PCN fazem alusão à Resolução de Problemas Matemáticos como um caminho para se fazer matemática em sala de aula. A proposta dos PCN se fundamenta nos seguintes princípios:

O ponto de partida da atividade matemática não é a definição, mas o problema. No processo de ensino e aprendizagem, conceitos, ideias e métodos matemáticos devem ser abordados mediante a exploração de problemas, ou seja, de situações em que os alunos precisem desenvolver algum tipo de estratégia para resolvê-las; o problema certamente não é um exercício em que o aluno aplica, de forma quase mecânica, uma fórmula ou um processo operatório. Só há problema se o aluno for levado a interpretar o enunciado da questão que lhe é posta e a estruturar a situação que lhe é apresentada; aproximações sucessivas ao conceito são construídas para resolver um certo tipo de problema; num outro momento, o aluno utiliza o que aprendeu para resolver outros, o que exige transferências, retificações, rupturas, segundo um processo análogo ao que se pode observar na história da Matemática; o aluno não constrói um conceito em resposta a um problema, mas constrói um campo de conceitos que tomam sentido num campo de problemas. Um conceito matemático se constrói articulado com outros conceitos, por meio de uma série de retificações e generalizações; a resolução de problemas não é uma atividade para ser desenvolvida em paralelo ou como aplicação da aprendizagem, mas uma orientação para a aprendizagem, pois proporciona o contexto em que se pode apreender conceitos, procedimentos e atitudes matemáticas (BRASIL, 1997, p. 33).

Nesse contexto, diversos autores se dedicaram a escrever e pesquisar sobre o assunto. Autores do campo da matemática ou mesmo autores de outras áreas, como da psicologia e pedagogia, por exemplo. Hoje, a Resolução de Problemas continua sendo pauta de muitos congressos, simpósios e encontros da área de matemática. Muitos grupos de estudos se dedicam a esta temática. O grupo de pesquisa em "Resolução de Problemas e educação matemática", da Universidade Estadual da Paraíba, e o "Grupo de trabalho e estudo em Resolução de Problemas em Educação Matemática", da Universidade Estadual Paulista Júlio

\footnotetext{
${ }^{2}$ Coordenado pela Professora Lourdes de la Rosa Onuchic - Doutora em Matemática pela USP.
} 
de Mesquita Filho" são exemplos de que as discussões sobre o tema são atuais, pertinentes e geram muitos resultados e investigações nas salas de aula. Com isso posto, a seguir abordaremos a Resolução de Problemas e sua relação com o ambiente escolar, alunos e professores.

\section{Resolução de Problemas Matemáticos: escola, aluno e professor}

A escola, por anos, apresentou-se como uma instituição tradicional de ensino. Livros, lousa, cadernos e canetas eram tidos como suficientes para o fornecimento do conhecimento aos alunos. O professor, por sua vez, assumia o papel de transmissor do conteúdo, reiterando fórmulas e resolvendo mecânicos e repetitivos exercícios. Diversos autores questionam essa maneira de se trabalhar na escola. Moysés (2010) é uma delas, apresentando em suas escritas uma crítica ao "extremo isolamento que cresce a cada dia na escola em relação ao mundo que a rodeia" (p. 59). Contudo, ao considerarmos esse lugar (Instituição Escolar) como um dos principais responsáveis por inserir o aluno na sociedade, modificando-a e sendo modificado por ela, precisamos voltar nossos olhares para ele e, principalmente, para os processos que estão sendo utilizados nas relações de ensino-aprendizagem presentes em seu contexto. Nesse sentido, a Resolução de Problemas vem na tentativa de proporcionar uma metodologia diferenciada para o Ensino da Matemática.

Aprofundando nosso estudo das Resoluções de Problemas, Sternberg (2001) apresenta etapas que por ele são consideradas necessárias ao se trabalhar com a Resolução de Problemas, a saber: identificação do problema, definição do problema, formulação de estratégia, organização das informações, alocação de recursos, monitoramento e avaliação. Segue abaixo um quadro que elaboramos com uma breve descrição de cada uma dessas etapas.

Quadro 2 - Etapas da Resolução de Problemas segundo Sternberg

\begin{tabular}{|c|l|}
\hline ETAPAS & BREVE DESCRIÇÃO \\
\hline $\begin{array}{c}\text { Identificação do } \\
\text { Problema }\end{array}$ & $\begin{array}{l}\text { Busca reconhecer a meta do problema. É uma constatação de sua } \\
\text { questão central. }\end{array}$ \\
\hline $\begin{array}{c}\text { Definição do } \\
\text { Problema }\end{array}$ & $\begin{array}{l}\text { Encarregado de definir o problema e representá-lo em nível } \\
\text { suficiente de compreensão para a sua solução. }\end{array}$ \\
\hline $\begin{array}{c}\text { Formulação de } \\
\text { Estratégia }\end{array}$ & É um prévio planejamento para que o problema seja resolvido. \\
\hline $\begin{array}{c}\text { Organização das } \\
\text { Informações }\end{array}$ & $\begin{array}{l}\text { Visa integrar todas as informações de modo conveniente à tarefa } \\
\text { do momento. Possibilita, com isso, uma melhor maneira de }\end{array}$ \\
\hline
\end{tabular}


implementar sua estratégia.

Corresponde à alocação e à organização de recursos mentais. Alocação de Recursos Assim, fica mais claro, atribuir maior tempo e dedicação na resolução de um problema.

Permite testar sua atuação durante toda a resolução de um

Monitoramento

Avaliação problema com o intuito de assegurar-se de que a meta do problema está sendo bem direcionada.

É um processo contínuo que pode ocorrer durante o problema, ao final dele ou, mesmo mais tarde, à sua solução.

Fonte: o autor.

No passo denominado por "Formulação de Estratégia", Sternberg (2001) sugere duas ramificações que a estratégia pode envolver: Análise e Síntese. A análise consiste em seccionar o problema em problemas mais simples. Como maneira de colaboração, o passo "formulação de estratégia" pode envolver o processo complementar de síntese que significa “agrupar vários elementos para dispô-los em algo útil” (p. 384). Além disso, tal passo, segundo o autor, envolve dois tipos de pensamento: divergente e convergente. O pensamento divergente diz respeito a promover um conjunto de diferentes soluções possíveis para um determinado problema. Após análise das diversas soluções, emprega-se o pensamento convergente a fim de transformar as diferentes possibilidades numa única possibilidade, sendo esta o melhor dos caminhos encontrados para a solução do problema.

Sternberg (2001) ressalta ainda a necessidade de flexibilização ao seguir os passos descritos acima, sendo possível retroagir ou avançar ao longo das etapas, alterar a ordem, agregar etapas ou até mesmo omitir alguma delas. Vivemos claramente essa necessidade de flexibilização ao planejarmos uma aula. Ao idealizarmos a maneira que trabalharemos um determinado conteúdo de matemática numa turma, sabemos ou deveríamos ter a consciência de que todo o plano pode não ser fielmente executado. Assim, é o caso das etapas apresentadas por Sternberg (2001). O foco do autor está na individual Resolução de Problemas. Porém, os resultados e as soluções obtidos em grupo, ressalta o autor, podem ser melhores do que os determinados individualmente.

Reforçando a ideia apresentada pelos PCN (BRASIL, 1997) a respeito das Resoluções de Problemas, Dante (2000) considera a metodologia da Resolução de Problemas como o melhor caminho para desenvolver no aluno um pensamento produtivo. Para o autor, ensinar a resolver problemas é uma tarefa bem mais difícil que ensinar um conteúdo ou um conceito matemático. É uma maneira de ensino que requer do aluno variáveis de pensamento produtivo 
que oportunizam sua presente ação em todo processo, com incentivo e acompanhamento do professor. Para Dante (2000, p. 49), “O real prazer de estudar matemática está na satisfação que surge quando o aluno, por si só, resolve um problema. Quanto mais difícil, maior a satisfação em resolvê-lo". Os problemas incentivam os alunos e possibilitam a eles um real envolvimento com a matemática. É motivacional, uma vez que proporcionam aos alunos a autossuperação.

Mais do que nunca precisamos de pessoas ativas e participantes, que deverão tomar decisões rápidas e, tanto quanto possível, precisas. Assim, é necessário formar cidadãos matematicamente alfabetizados, que saibam como resolver, de modo inteligente, seus problemas de comércio, economia, administração, engenharia, medicina, previsão do tempo e outros da vida diária. E, para isso, é preciso que a criança tenha, em seu currículo de matemática elementar, a resolução de problemas como parte substancial, para que desenvolva desde cedo sua capacidade de enfrentar situaçõesproblema (DANTE, 2000, p. 15).

Cabe ressaltar que os PCN não preconizam a Resolução de Problemas apenas para o ensino fundamental, mas também reforçam sua importância no ensino médio. Essa perspectiva metodológica voltada para o nível médio deve ser entendida como um processo de investigação perante qualquer situação ou qualquer fato que possa ser questionado. Fica claro, com isso, que sua importância não está na resposta final de um problema, mas no seu processo e naquilo que pode ser desencadeado no aluno.

Resolver um problema não se resume em compreender o que foi proposto e em dar respostas aplicando procedimentos adequados. Aprender a dar uma resposta correta, que tenha sentido, pode ser suficiente para que ela seja aceita e até seja convincente, mas não é garantia de apropriação do conhecimento envolvido (BRASIL, 1997, p. 45).

Ao se trabalhar com a metodologia da Resolução de Problemas, alguns autores, como Van de Walle (2001), destacam o entusiasmo que certos alunos desenvolvem a partir do desafio proporcionado pelos problemas ou mesmo pelo desenvolvimento da capacidade de compreensão que experimentam por meio de seus próprios raciocínios. Smole (2010) trata da importância da superação do obstáculo pelo resolvedor de um problema. A autora, assim como traz Dante (2000) e os PCN (BRASIL, 1997), ressalta que problema não é uma situação focada em encontrar uma resposta de forma rápida, mas o cerne deve estar nas decisões a serem tomadas na tentativa de alcançar o objetivo previamente definido pelo próprio resolvedor do problema, ou mesmo um objetivo que lhe foi proposto. Esse processo é quem 
vai apresentar o envolvimento, a interação e o quanto o aluno se sente desafiado perante a situação-problema proposta.

Essa estratégia está centrada na ideia de superação de obstáculo pelo resolvedor, devendo, portanto, não ser de resolução imediata pela aplicação de uma operação ou fórmula conhecida, mas oferecer uma resistência suficiente, que leve o resolvedor a mobilizar seus conhecimentos anteriores disponíveis, bem como suas representações, e seu questionamento para a elaboração de novas ideias e de caminhos que visem a solucionar os desafios estabelecidos pela situação problematizadora, gerando então novas aprendizagens e formas de pensar (SMOLE, 2010, p. 12).

Refletirmos sobre a relação de ensino e aprendizagem na escola e trazermos a Resolução de Problemas para esse contexto é também identificarmos a própria aula como um espaço de problematização (SMOLE, 2010). Os alunos, com isso, deparam-se com constantes desafios e inquietações por meio dos quais formulam ideias, fazem testes, criam hipóteses, pensam criticamente a partir de experiências bem sucedidas, refletem a partir das experiências que não obtiveram êxito, formulam argumentações, socializam com os colegas de turma resultados e caminhos percorridos, bem como promovem discussões a respeito do problema. Enfim, requer que o aluno promova um processo de investigação científica a respeito daquilo que está sendo resolvido, aprendendo e valorizando sempre o espírito de investigação (SANTOS, 2008).

Ao refletir sobre o papel da Resolução de Problemas no que se refere ao incentivo e à aprendizagem da investigação, esbarramo-nos no fazer profissional do professor. Talvez, a matemática seja uma das áreas de conhecimento onde o tradicionalismo seja mais evidente. Isso pode ser justificado pelo fato de muitos professores, mesmo com o avanço da Educação Matemática, ainda se prevalecer de ultrapassados métodos de ensino. Muitos profissionais ainda ficam presos ao quadro, caneta e livros didáticos e não se dão a oportunidade de se reciclar, de fazer diferente, de olhar para outros recursos que estão tão presentes em nosso cotidiano, mas que os isolamos da sala de aula. E, não é só questão de não se dar a oportunidade, mas é, principalmente, de impossibilitar que o discente tenha a chance de conhecer a matemática de maneira diferenciada e mais atrativa. Isso faz com que o lado puramente abstrato da matemática fique ainda mais evidenciado para os alunos, bem como a memorização de fórmulas e algoritmos para a Resolução de Problemas, características estas que podem desestimular ainda mais os alunos no estudo da matemática e que pode afastar o processo investigatório que a Resolução de Problemas, por vezes, exige. 
Ao se trabalhar com a Resolução de Problemas, o professor precisa se afastar de um modelo puramente tradicional de educação, onde o mesmo é considerado o detentor de todo o conhecimento, enquanto o aluno é vazio e sem conteúdo. A relação aluno/professor está focada no docente e na unilateralidade na transmissão do conhecimento neste modelo de ensino. Muitos pesquisadores, como Paulo Freire e Ubiratan D'Ambrósio, posicionaram suas escritas no sentido de superar esse padrão tradicional de ensino. De acordo com os PCN (BRASIL, 1998), diferentes metodologias de ensino devem fazer parte da atividade docente. Sendo assim, ao considerarmos a Resolução de Problemas como uma metodologia de ensino e um caminho para se trabalhar com a matemática em sala de aula, distanciaremos o nosso olhar do papel do professor puramente tradicional.

George Pólya (1995), uma de nossas referências bibliográficas sobre a Resolução de Problemas, traz-nos também reflexões a respeito do papel do professor nas relações de ensino e aprendizagem no trabalho dessa metodologia. Pólya (1995), então, publicou dez regras que julga necessárias para a prática docente. A seguir, listaremos todas elas e posteriormente faremos referências a algumas delas ao relatar nossa visão sobre os temas elencados.

Quadro 3 - Os Dez Mandamentos para Professores segundo Pólya

\begin{tabular}{|c|c|}
\hline & OS DEZ MANDAMENTOS PARA PROFESSORES \\
\hline 1 & Tenha interesse por sua matéria; \\
\hline 2 & Conheça sua matéria; \\
\hline 3 & $\begin{array}{l}\text { Procure ler o semblante dos seus alunos; procure descobrir as suas expectativas e as } \\
\text { suas dificuldades; ponha-se no lugar deles; }\end{array}$ \\
\hline 4 & $\begin{array}{l}\text { Compreenda que a melhor maneira de aprender alguma coisa é descobri-la você } \\
\text { mesmo; }\end{array}$ \\
\hline 5 & $\begin{array}{l}\text { Dê aos seus alunos não apenas informação, mas know-how, atitudes mentais, o } \\
\text { hábito de trabalho metódico; }\end{array}$ \\
\hline 6 & Faça-os aprender a dar palpites; \\
\hline 7 & Faça-os aprender a demonstrar; \\
\hline 8 & $\begin{array}{l}\text { Busque, no problema que está abordando, aspectos que poderão ser úteis nos } \\
\text { problemas que virão - procure descobrir o modelo geral que está por trás da } \\
\text { presente situação concreta; }\end{array}$ \\
\hline 9 & $\begin{array}{l}\text { Não desvende o segredo de uma vez - deixe os alunos darem palpites antes - na } \\
\text { medida do possível, deixe-os descobrir por si próprios; }\end{array}$ \\
\hline 10 & Sugira, não os faça engolir à força. \\
\hline
\end{tabular}
Fonte: $\mathrm{O}$ autor.

Apesar da tendência de colocar o aluno como co-construtor do conhecimento ser evidenciada e marcada num período posterior ao de Pólya, percebemos nesses mandamentos que o posicionamento do professor deve estar longe de uma postura tradicional ao se trabalhar 
com a Resolução de Problemas. Infere-se que o professor não é um transmissor do conteúdo, e o aluno apenas um agente passivo nesse processo. Ao recomendar que o docente deixe os alunos darem palpites, é possível notar que devemos considerar o conhecimento prévio do aluno e seus processos mentais. Há uma valorização do aluno, colocando-o numa posição de importância na aprendizagem e exaltando, mesmo que implicitamente, seus conhecimentos.

Pólya (1995), ao aconselhar que não devemos fazer com que o aluno engula à força as propostas de ensino, propõe a necessidade de transformarmos nosso aluno em um aluno pesquisador que, como parte principal de todo o processo, participa ativamente e criticamente de toda sua formação. O quarto mandamento também ratifica esse pensamento, uma vez que propicia ao aluno a oportunidade de avançar na Resolução de um Problema através de seus próprios erros e acertos. É um processo investigativo, cujo professor irá ser um mediador: alertando o aluno, desafiando-o, fazendo-o descobrir, incentivando-o a dar palpites, a refletir criticamente, a criar, a formular e reformular ideias e até mesmo possíveis generalizações (SOARES; PINTO, 2001).

Segundo Dante (2000), os professores têm razões pelas quais devem fazer uso das Resoluções de Problemas de Matemática em sala de aula. Ele cita o desenvolvimento do raciocínio, do pensamento produtivo e o enriquecimento da aula com desafios que tornam o encontro mais atrativo como algumas das razões para o professor trabalhar sobre o pilar da Resolução de Problemas. Ao propor um problema, as autoras Soares e Pinto (2001) citam importantes características que o professor deve observar, como propiciar a discussão e a socialização dos caminhos encontrados na Resolução do Problema, mesmo sendo caminhos considerados errados; estimular a verificação da solução e incentivar ideias e novos questionamentos.

A reflexão sobre o Ensino da Matemática é de suma relevância para o professor e deve fazer parte de suas atividades em todo o seu tempo de trabalho. A Resolução de Problemas dentro desse contexto do Ensino da Matemática, pregada pelos PCN como um dos caminhos de se fazer matemática na sala de aula, requer do professor uma análise das variáveis envolvidas nesse processo (aluno, professor e saber matemático) e das relações existentes entre elas. Com isso, os PCN citam como fundamental importância o professor:

Identificar as principais características dessa ciência, de seus métodos, de suas ramificações e aplicações; Conhecer a história de vida dos alunos, sua vivência de aprendizagens fundamentais, seus conhecimentos informais sobre um dado assunto, suas condições sociológicas, psicológicas e culturais; Ter clareza de suas próprias concepções sobre a Matemática, uma vez que a prática em sala de aula, as escolhas pedagógicas, a definição de objetivos e 
conteúdos de ensino e as formas de avaliação estão intimamente ligadas a essas concepções. (BRASIL, 1997, p. 29).

Ao se trabalhar com a perspectiva da Resolução de Problemas, os PCN ressaltam ainda que o papel do professor deve ganhar novas dimensões. Inclui nesse novo posicionamento para o professor ser

organizador da aprendizagem: preocupa-se inclusive com a escolha dos problemas a serem trabalhados. Estes devem propiciar a construção de conceitos, além de levar em consideração competências cognitivas do aluno, sua expectativa e suas questões socioculturais. Uma má organização pode frustrar todo o objetivo previamente construído e possivelmente gerará incômodos nos alunos envolvidos neste processo de aprendizagem; consultor: não está preocupado somente com a exposição do conteúdo, mas em fornecer informações necessárias para que o aluno alcance o objetivo. Para isso, o professor oferece textos, tecnologias, explicações e diversos outros materiais que cooperem com o desenvolvimento das estratégias utilizadas pelos alunos no ataque a um problema; mediador: preocupa-se em contestar o aluno, em promover o confronto das propostas apresentadas por eles, orientar reformulações, além de promover o debate sobre os métodos utilizados, valorizando as soluções mais adequadas e considerando o conhecimento prévio dos alunos; controlador: no sentido de estabelecer prazos e condições para a realização da atividade proposta; incentivador da aprendizagem: visa proporcionar a cooperação entre alunos. É uma significativa forma de aprendizagem, uma vez que na troca com o colega ou mesmo com o professor, o aluno formula argumentos, realiza o exercício de convencimento a partir de sua visão para o problema, exerce a argumentação e promove conhecimento através das trocas proporcionadas pelo incentivo do professor à aprendizagem. Além de desempenhar um fundamental papel na formação afetiva entre os alunos ou mesmo entre o aluno e o professor (BRASIL, 1997, p. 27).

Percebe-se, até então, que, ao se trabalhar com a Resolução de Problemas, há a necessidade de uma transformação na postura do professor. Essa mudança está intimamente relacionada com a formação do profissional da Educação, uma vez que somos também reflexos de nossa vida acadêmica e, muitas vezes, tomamos como parâmetro para nosso fazer profissional professores com os quais nos deparamos durante nossa formação. Até porque nossa profissão tem o privilégio de ter a própria formação acadêmica como palco de experiências para a profissionalização. D'Ambrósio (1993) traz isso em seus escritos ao dizer que, normalmente, temos contato com uma formação pronta e acabada e isso acaba frequentemente refletindo em nosso trabalho como professor.

Sendo assim, enfatizamos a importância de que a metodologia da Resolução de Problemas incorpore a formação acadêmica inicial do professor para que o tal profissional já 
se familiarize e se integre a ela, favorecendo, assim, a formação do docente, bem como a aprendizagem dos seus futuros alunos. Cabe enfatizar que essa integração não deve ser só do ponto de vista teórico, mas que, durante a formação, o professor possa ter contato com a integração entre teoria e prática baseada nessa vertente, tendo como objetivo principal a sua indissociabilidade.

\section{Finalizando a conversa... desafios da resolução de problemas}

Um dos desafios encontrados no trabalho com a Resolução de Problemas está no próprio enunciado do problema, o que faz com que, por vezes, seja necessário realizar adaptações e releituras dos enunciados a fim de eliminar ambiguidades e possíveis erros. Nessa questão, o professor precisa ter cuidado para que o aluno não se torne dependente da leitura e da interpretação do professor. O problema não pode ser ambíguo; sua linguagem precisa estar em consonância com o nível de escolaridade dos alunos e necessita ser claro o suficiente para que o discente desempenhe de forma mais independente possível sua interpretação. Tem-se, com isso, "a necessidade de os professores desenvolverem uma compreensão sólida e flexível do terreno matemático que seus alunos irão atravessar" (STEIN; BOALER; SILVER, 2003, p. 256).

Outro desafio é a dificuldade que muitos alunos têm na leitura e compreensão do enunciado de um problema. Às vezes, os obstáculos nem são os conceitos matemáticos em si, mas a falta de interpretação do problema. O professor, ao mediar esse processo, esclarecendo o enunciado para o aluno ou mesmo somente lendo em voz alta o problema para ele, percebe que as ideias de caminhos a tomar na tentativa de solucionar a situação-problema começam a ganhar corpo e a se apresentar de forma mais consistente por parte dos alunos.

O aluno muitas vezes não resolve o problema de matemática, não porque não saiba matemática, mas porque não sabe ler o enunciado do problema. Ele sabe somar, dividir etc., mas ao ler um problema não sabe o que fazer com os números e a relação destes com a realidade a que se referem. Não adianta dizer que o aluno não sabe nem sequer somar ou dividir números que não apresentam dificuldades, que ele não entende matemática... Porque de fato ele não entende mesmo é o português que lê. Não foi treinado para ler números, relações quantitativas, problemas de matemática. $\mathrm{O}$ professor de língua portuguesa não ensina isso porque diz que é obrigação do professor de matemática e o professor de matemática ou não desconfia do problema ou, quando muito, acha que ler e compreender um texto é um problema que o professor de língua portuguesa deve resolver na educação das crianças. Mas a escola cobra que ela saiba isso e se vire com perfeições e rapidez (CAGLIARI, 2010, p. 130). 
Um outro desafio constante na vida do professor de matemática está no resgaste da motivação que muitos alunos perderam com relação à área de conhecimento em questão. A matemática já é temida por muitos, e isso acaba por afastar ainda mais as pessoas dela. E, ao considerarmos que o interesse precede o bom resultado, torna-se fundamental animar os alunos a aprender matemática. Sem o despertar do interesse e da motivação, torna-se difícil fazer um bom trabalho com o aluno. Então, cabe também ao professor o empenho no sentido de tornar a matemática mais agradável e interessante. A inquietação proposta por um problema, por exemplo, pode ser uma saída motivacional. Para isso, a escolha dos problemas também exerce impactos no desenvolvimento desses sentimentos no aluno, aguçando a curiosidade e estimulando a criatividade (SOARES; PINTO, 2001).

Ao considerar o aluno como co-construtor de todo o processo de ensino e aprendizagem, o professor também é desafiado no sentido de não tornar sua relação com o aluno unilateral. Não cabe ao professor o poder do conhecimento, a detenção do saber, nem mesmo a sua pura transmissão. Ao mesmo tempo, também não cabe considerar o discente como o único encarregado pelo processo de aquisição do conhecimento. Entender o papel tanto do professor quanto do aluno nesse processo interfere positivamente nos percalços de aprendizagem encontrados ao se trabalhar com a Resolução de Problemas.

\section{Referências}

ALleVAtO, N. S. G. Associando o computador à Resolução de Problemas Fechados: Análise de uma experiência. 2005. 378 f. Tese (Doutorado em Educação Matemática) Instituto de Geociências e Ciências Exatas, Universidade Estadual Paulista, Rio Claro, 2005.

ALVARENGA, D.; VALE, I. A exploração de problemas de padrão: um contributo para o desenvolvimento do pensamento algébrico. Quadrante, Portugal, v. 16, n. 1, p. 27 -55, 2007.

ANDRADE, S. Ensino-aprendizagem de matemática via resolução, exploração, codificação e descodificação de problemas. 1998. 295 f. Dissertação (Mestrado) - Instituto de Geociências e Ciências Exatas, Universidade Estadual Paulista, Rio Claro, 1998.

BRASIL, Ministério da Educação Secretaria de Educação Média e Tecnológica. Parâmetros Curriculares Nacionais: Ensino Médio: Ciências da Natureza, Matemática e suas Tecnologias. Ministério da Educação. Brasília: SMT/MEC, 1997. Disponível em: http://portal.mec.gov.br/seb/arquivos/pdf/livro03.pdf. Acesso em: 12 abr. 2019.

BRASIL. Ministério da Educação. Secretaria de Educação Média e Tecnológica. Parâmetros Curriculares Nacionais: Ensino Médio: Ciências da Natureza, Matemática e suas 
Tecnologias. Ministério da Educação. Brasília: SMT/MEC, 1998. Disponível em: http://portal.mec.gov.br/seb/arquivos/pdf/matematica.pdf. Acesso em: 12 abr. 2019.

CAGLIARI, L. C. Alfabetização e Linguística. São Paulo: Scipione, 2010.

CARVALHO, J. P. de. Os três problemas clássicos da matemática grega. Programa de Iniciação Ciêntífica - PIC, OBMEP, 19 de agosto 2010.

CAVAlCANTI, L. B.; BRANCO, J. C.; SANTOS, L. M. S. Arte de Resolver Problemas. V Colóquio Internacional Educação e Contemporaneidade, UNICAMP, 2011.

CHARNAY, R. Aprendendo (com) a resolução de problemas. In: PARRA, C. (org.). Didática da Matemática: reflexões psicopedagógicas. Porto Alegre: Artes Médicas, 1996. p. 36-47.

COSTA, M. S.; AllevatO, N. S. G. . Construindo uma nova metodologia de EnsinoAprendizagem-Avaliação nos anos finais do Ensino Fundamental através da resolução de problemas de Geometria. In: X ENEM - X Encontro Nacional de Educação Matemática, 2010, Salvador. Anais do X ENEM. Recife/PE: Sociedade Brasileira de Educação Matemática, 2010. v. Único. p. 1-9.

D’AMBRÓSIO, B. S. Formação de professores de matemática para o século XXI: o grande desafio. Pro-Posições, Campinas, v. 4, n. 1, p. 35-41, mar. 1993.

DANTE, L. R. Didática da resolução de problemas de matemática. São Paulo: Ática, 2000.

DEMO, P. Educação e qualidade. Campinas, SP: Papirus, 2015.

KENSKI, V. M. Educação e Tecnologias: o novo ritmo da informação. 3. ed. Campinas, SP: Papirus, 2008.

LESTER, F. Por que o ensino com resolução de problemas é importante para a aprendizagem do aluno? Boletim GEPEM, Rio de Janeiro, n. 60, p. 147 -162, 2012.

LORENZATO, S.; VILA, M. do C. Século XXI: qual matemática é recomendável?. Zetetiké, Campinas, v. 1, n. 1, p. 41-50, 1993.

LUPINACCI, M. L. V.; BOTIN, M. L. M. Resolução de problemas no ensino de matemática. Anais do VIII Encontro Nacional de Educação Matemática, Recife, p. 1-5, 2004.

MINAYO, M. C. S. O desafio da pesquisa social. In: MINAYO, M. C. S. (Org.). Pesquisa social: teoria, método e criatividade. 28. ed. Petrópolis, RJ: Vozes, 2009. Cap. 1, p. 9-30. 
MOYSÉS, L. Aplicações de Vygotsky à educação matemática. 10. ed. Campinas, SP: Papirus, 2010.

ONUCHIC, L. R. Ensino-aprendizagem de Matemática através da resolução de problemas. In: BICUDO, M. A. V. (Org.). Pesquisa em Educação Matemática. São Paulo: Editora UNESP, 1999. cap.12, p.199-220.

PÓLYA, G. A arte de resolver problemas: um novo aspecto do método matemático. Rio de Janeiro: Interciência, 1995.

POZO, J. I.; ECHEVERRÍA, M. D. P. P. Aprender a resolver problemas e resolver problemas para aprender. In: POZO, Juan Ignacio. A solução de problemas: aprender a resolver, resolver a aprender. Porto Alegre: Artmed, 1998.

RAIGORODSKII, A. M. The Borsuk partition problem: the seventieth anniversary. The mathematical intelligencer, vol. 26, n. 3, p. 4-12, 2004.

SANTOS, V. C. P. Matlhlets: Possibilidades e Potencialidades para uma Abordagem Dinâmica e Questionado no Ensino da Matemática. 2008. Disponível em:

$<$ http://www.pg.im.ufrj.br/pemat/02\%20Victor\%20Paixao.pdf $>$. Acesso em: 15 mar. 2017.

SCHROEDER, T. L.; LESTER JR, F. K. Developing Understanding in Mathematics via Problem Solving. In: TRAFTON, P. R.; SHULTE, A. P. (Ed.). New Directions for Elementary School Mathematics. Reston: NCTM, 1989. p. 31-42.

SMOLE, K. S. Resolução de Problemas e Pensamento Matemático. 2010. Disponível em: $<$ http://www.edicoessm.com.br/sm_resources_center/somos_mestres/formacao-reflexao/afrevistavj-2010.pdf $>$. Acesso em: $0 \overline{3}$ mar. $201 \overline{7}$.

SOARES, M. T. C.; PINTO, N. B. Metodologia da resolução de Problemas. $24^{a}$ Reunião Anual da ANPED, Caxambu, MG, 2001.

STEIN, M. K.; BOALER, J.; SILVER, E. A. Teaching Mathematics through Problem Solving: Research Perspectives. In: SCHOEN, H. L. (Ed.). Teaching Mathematics through Problem Solving: Grades 6-12. Reston, VA: NCTM, 2003. p. 245-256.

STERNBERG, R. J. Psicologia Cognitiva. Trad. Maria Regina Borges Osório. Porto Alegre: Artes Médicas Sul, 2001.

VAN DE VALLE, J. A. Elementary and Middle School Mathematics. New York: Longman, 2001.

VERÇOSA, M.; ROCHA, S.; TELES, R. A. M. Resolução de problemas matemáticos: aproximações e distanciamentos nos anos iniciais do Ensino Fundamental. Revista TCC Revista de divulgação científica do curso de Pedagogia - UFPE, v. 1, p. 1-20, 2010. 